\title{
THREE DIMENSIONAL ASSESSMENT OF THE PHARYNGEAL AIRWAY IN A SAMPLE OF EGYPTIAN CHILDREN WITH AND WITHOUT CLEFT LIP AND PALATE
}

\author{
Ghadeer M. I. Al-Hout ${ }^{*}$, Abbadi A . El-kadi** and Sherif S. Morcos***
}

\begin{abstract}
Objective: to compare the pharyngeal airway dimensions among cleft lip and palate patients and non-cleft lip and palate patients by using Cone-beam computed tomography (CBCT).

Material and methods: The sample included 60 cone-beam computed tomography (CBCT) of patients both males and females with age range 8-12 years, 30 patients with cleft lip and palate and 30 patients with non-cleft lip and palate. Measurements including Oropharnx linear measurment (width and depth), Nasopharynx linear measurment (width and depth) and Volumetric analysis( oropharynx and nasopharynx) were made digitally on 3-dimensional based dental software (In Vivo Dental, Anatomage, San Jose, CA, USA).
\end{abstract}

Results: For all cases including males and females, results showed statistically significant differences between control and cleft groups in oropharynx measurements (depth and volume) and in nasopharynx width.. 10 patient CBCT records in cleft and control groups were randomly selected and all measurements were repeated to test intraexaminer and interexaminer reliability respectively. For reliability evaluation results showed excellent agreement between measurements at two different time intervals.

Conclusion: Oropharyngeal airway space (depth-width and volume) and nasopharyngeal (width). significantly decreased in cleft than control patient.

KEY WORDS: CBCT; Cleft lip; Cleft palate; Oropharynx; Nasopharynx.

\section{INTRODUCTION}

Children with cleft lip and palate (CLP) are known to have airway problems. CLP are frequently associated with nasal abnormalities such as septal deviation, nostril atresia, turbinate hypertrophy, maxillary constriction, vomerine spurs, and alar constriction, these nasal abnormalities tend to reduce the dimensions of the nasal cavity and lower airway function.

* Canditate, Masters Degree Programme, Orthodontic dept., Faculty of Dentistry, Suez Canal University.

** Professor, Orthodontic dept. Faculty of Dentistry, Suez Canal University.

*** Lecturer, Orthodontic dept., Faculty of Dentistry, Suez Canal University. 
Airway patency has been evaluated by twodimensional (2D) radiographic imaging such as lateral and anterior-posterior cephalometric radiographs and functional studies such as rhinomanometry and plethysmography. Lateral cephalometric radiographs of children with CLP were compared with non-cleft controls and showed a reduction in the nasopharyngeal bony framework and pharyngeal airway. Furthermore, a reduction in the upper airway in juveniles with CLP was found when compared to gender and age matched non-cleft controls and was found to persist through adolescence when lateral cephalometric radiographs were compared.

Yoshihara et $\mathrm{al}^{1}$ evaluated the pharyngeal airway morphology in girls, found statistically significant decrease in oropharyngeal airway (width, height and volume) between the cleft and control group.

Cheung and Oberoi ${ }^{2}$ studied the CBCT data of pre-adolescent individuals. Volume and smallest cross-sectional were studied. They found that the individuals with CLP did not exhibit smaller total airway volume and cross sectional area than nonCLP controls.

The present work compared the pharyngeal airway dimensions among cleft lip and palate patients and non-cleft lip and palate patients by using Cone-beam computed tomography (CBCT).

\section{MATERIALS AND METHODS}

Our sample included 60 cone-beam computed tomography (CBCT) of patients both males and females with age range 8-12 years, 30 patients with cleft lip and palate and 30 patients with non-cleft lip and palate. Patients' CBCT of this study were selected from one scanning centers with the same scanning parameters.

The sample was divided into two groups:

A) First group ( cleft lip and palate group): included 30 cleft lip and palate patients who were not subjected to any comprehensive orthodontic procedure.

\section{B) Second group (non-cleft lip and palate group):} included 30 non- cleft lip and palate patients who were not subjected to any comprehensive orthodontic procedure.

Inclusion criteria include the following:

A) Vertical Dental and skeletal abnormality.

B) Antroposterior Dental and skeletal abnormality.

C) Transverse Dental and skeletal abnormality.

CBCT images were acquired using a Next Generation i-CAT scanner (Imaging Sciences International, Inc., Hatfield, USA). A scout view was obtained and adjustments were made to ensure that the all patients were correctly aligned in the scanner according to adjustment light beam before acquisition. The machine is supplied with Amorphous Silicon Flat Panel Sensor with Cesium Iodide (CsI) scintillator, $0.5 \mathrm{~mm}$ focal spot size, 14 Bit gray scale resolution, and operating at the following protocol for all the scans of the study After acquisition, data were exported and transferred in DICOM format.

The software In Vivo Dental (version5.1; Anatomage, San Jose, CA, USA) was used was used for image reconstruction from the Axial CT-scans.

The following measurements were taken for CBCT scans (Fig. 1\&2):

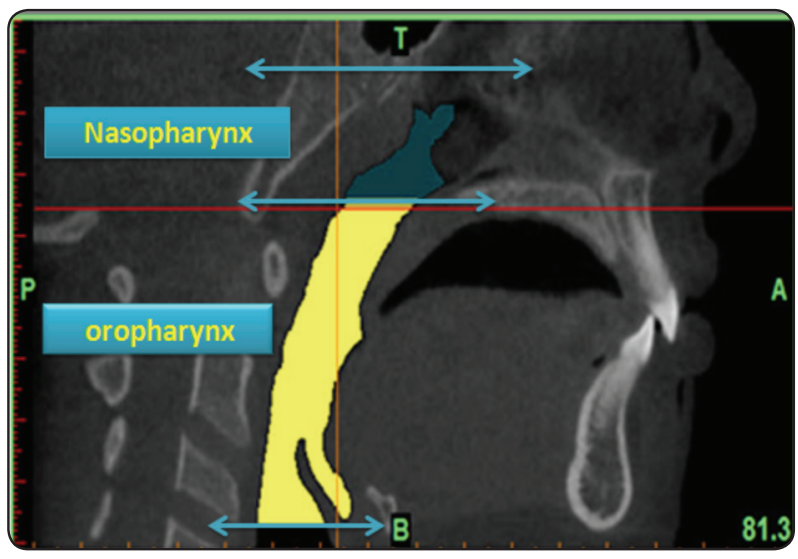

Fig. (1) CBCT image showing pharyngeal airway anatomy. 


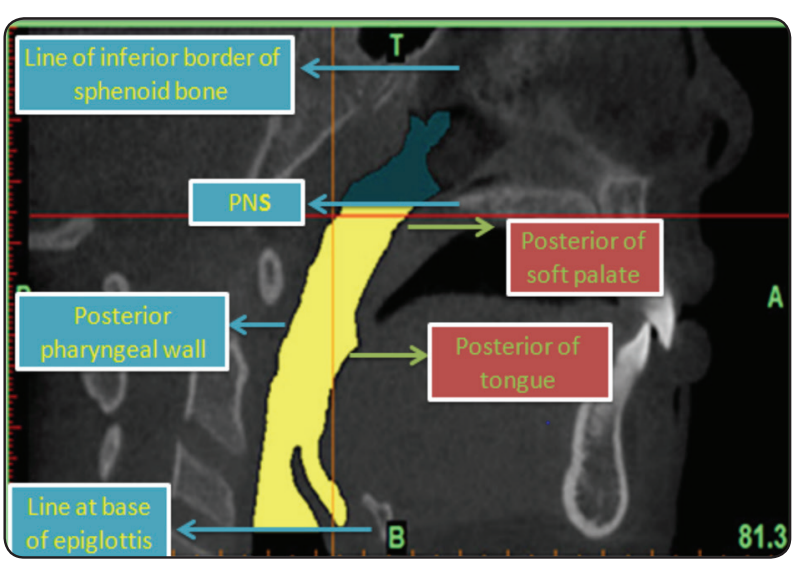

Fig. (2) CBCT image showing Borders of measured pharyngeal airways.

A) Oropharnx linear measurment (width and depth)

B) Nasopharynx linear measurment (width and depth)

C) Volumetric analysis (oropharynx and nasopharynx).

\section{A) Oropharnx linear measurment (width and depth):}

At the sagittal view; 3-D image was reoriented by reorientation tool provided by the software in order to adjust the axial reference line to be parallel to the Frankfurt plane (Orbitale-Porion). After previous adjustment, axial reference line was moved to intersect with Gonion at the coronal and sagittal views. In the produced axial image Oro-pharyngeal space was measured in two direction; width (mediolateral aspect), and depth (antero-posterior aspect). ${ }^{4}$ (Fig. 3)

\section{B) Nasopharynx linear measurment (width and depth):}

At the sagittal view, the volume was reoriented in such a way to align the axial reference line with the porion and first molars intercuspation at the right side. At the produced axial view, nasopharyngeal dimensions were measured in the same manner as in oro-pharynx width (mediolateral aspect), and depth (antero-posterior aspect). (Fig. 4)

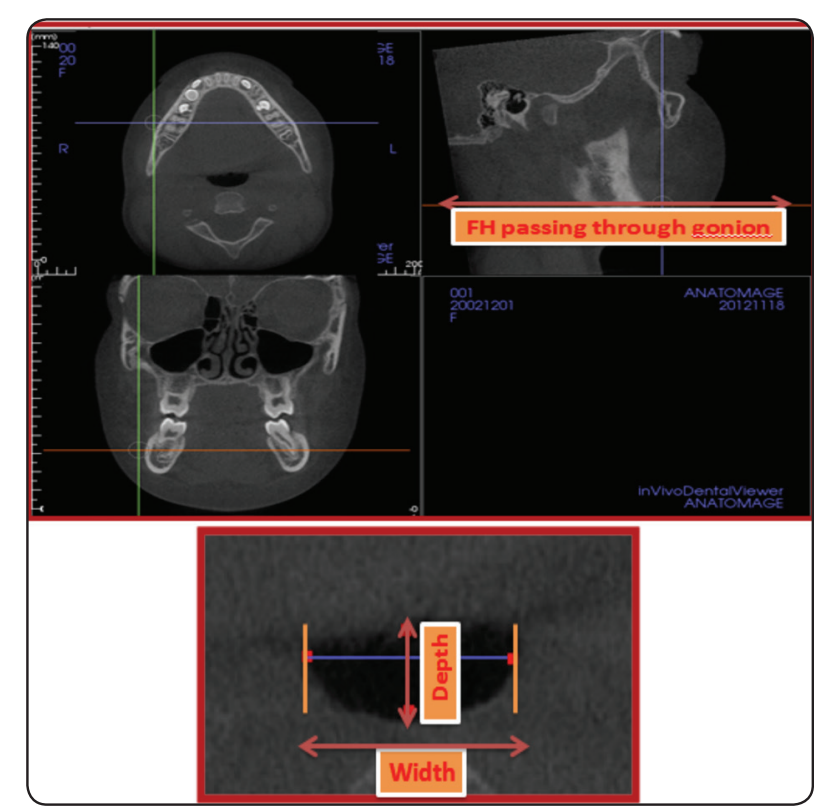

Fig. (3) CBCT image showing measurement of the oropharyngeal (OA) airway ( width and depth).

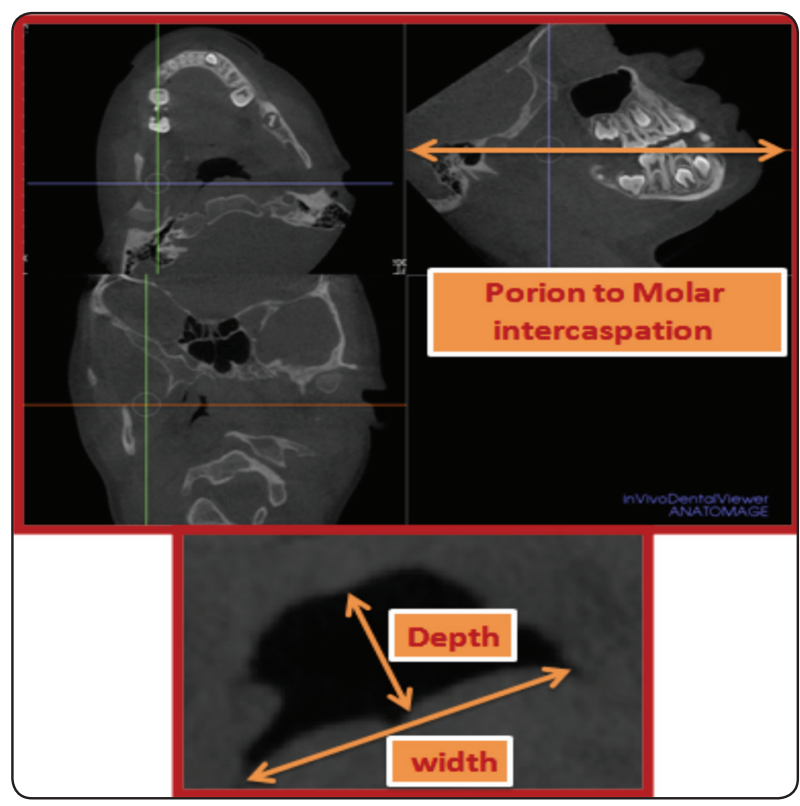

Fig. (4) CBCT image showing measurement of nasopharyngeal (NA) airway (width and depth).

\section{C) Volumetric analysis (oropharynx and nasopharynx):}

All CBCT images of both cleft and non-cleft groups were manipulated using another software for volume measurement. Mimics software 
(Materialise, Belgium) was used for volume calculation. After importing the DICOM files into the mimics software, a fixed threshold was assigned to create the desired mask were the assigned threshold corresponded to the density of airway. A targeted airway section was isolated by removing any unnecessary structures. The threshold value was established in a range from $-1,024$ to -300.5 After thresholding, cropping and region growing was adjusted to define the outlines of the oropharynx and nasopharynx. The anterior limit of the nasopharyngeal space between the inferior border of sphenoid bone to planes passing through PNS was defined by the coronal plane perpendicular to the FH plane and sagittal plane that passes through PNS. oropharyngeal space was defined as the airway space between the planes passing through PNS and the epiglottis base After defining the outline of oropharynx and nasopharynx, a separate mask was created for each one and its volume was automatically measured. ${ }^{6}$ (Fig. 5)

\section{Statistical analysis}

The data were collected, tabulated, and analyzed. Student $t$-test was used to test the difference in oropharyngeal and nasopharyngeal airway space (width, depth, and volume) between cleft and control cases.

Intraclass correlation coefficient was used to test intraexaminer reliability, 10 patient $\mathrm{CBCT}$ records in cleft and control groups were randomly selected and all measurements were repeate.

\section{RESULTS}

For intra-examiner reliability ICC values were ranging between 0.802 to 0.962 which reveal excellent agreement between measurements at two different time intervals. (Table 1)

For inter-examiner reliability ICC values were ranging between 0.802 to 0.911 which reveal excellent agreement between measurements at two different time intervals. (Table 2)

TABLE (1) Measurement made by one examiner:

\begin{tabular}{|c|c|c|c|}
\hline \multirow{4}{*}{ Oro pharyngeal } & \multirow{2}{*}{ Measurement } & \multicolumn{2}{|c|}{} \\
\cline { 3 - 4 } & ICC & P \\
\cline { 2 - 4 } & Width & 0.952 & $0.001 * * *$ \\
\cline { 2 - 4 } & Depth & 0.962 & $0.001 * * *$ \\
\cline { 2 - 4 } & Volume & 0.802 & $0.001 * * *$ \\
\hline \multirow{3}{*}{ Naso pharyngeal } & Width & 0.859 & $0.001 * * *$ \\
\cline { 2 - 4 } & Depth & 0.912 & $0.001 * * *$ \\
\cline { 2 - 4 } & Volume & 0.821 & $0.001 * * *$ \\
\hline
\end{tabular}

ICC. = Interclass correlation for absolute agreement.

$P \quad=$ Probability level for absolute agreement (ICC).

NS = Insignificant $(p>0.05)$.

$* * *=$ Significant at $p \leq 0.00$

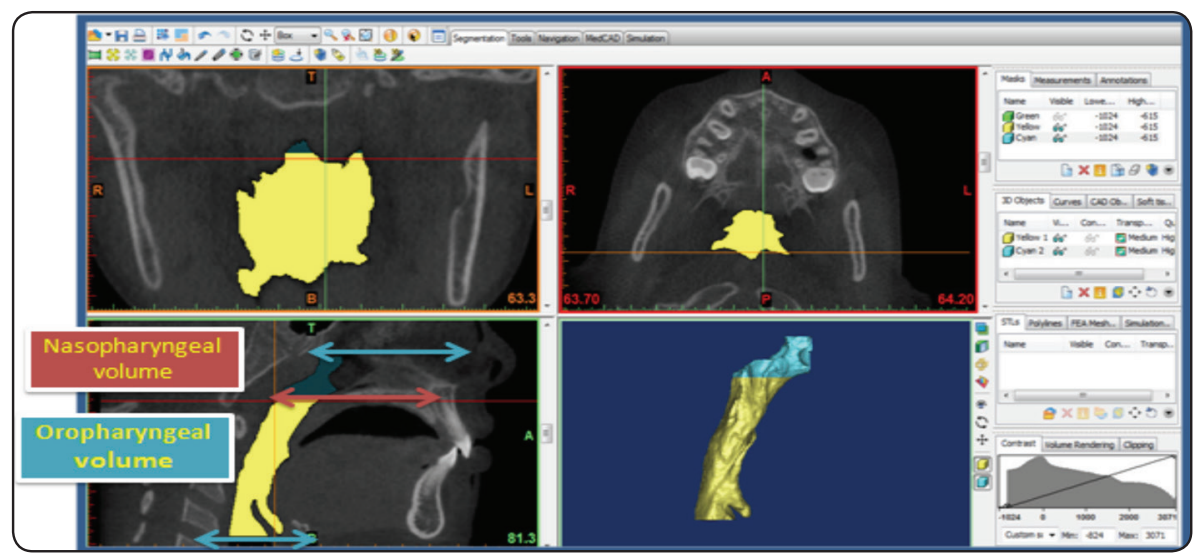

Fig. (5)

CBCT image showing measurement of oropharyngeal and nasopharyngeal airway volume. 
TABLE (2) Measurement made by two examiners:

\begin{tabular}{|l|c|c|c|}
\hline \multirow{2}{*}{ Measurement } & \multicolumn{2}{|c|}{} & \multicolumn{2}{|c|}{ P } \\
\cline { 2 - 4 } & Width & ICC & $0.001 * * *$ \\
\hline \multirow{3}{*}{ Oro Pharyngeal } & Depth & 0.843 & $0.001 * * *$ \\
\cline { 2 - 4 } & Volume & 0.911 & $0.001 * * *$ \\
\cline { 2 - 4 } & Width & 0.856 & $0.001 * * *$ \\
\cline { 2 - 4 } Naso Pharyngeal & Depth & 0.902 & $0.001 * * *$ \\
\cline { 2 - 4 } & Volume & 0.880 & $0.001 * * *$ \\
\hline
\end{tabular}

ICC. = Interclass correlation for absolute agreement.

NS = Insignificant $(p>0.05)$.
$P=$ Probability level for absolute agreement (ICC).

$* * *$ Significant at $p \leq 0.001$

For Oropharyngeal and Nasopharyngeal in oropharyngeal (depth and volume) $(\mathrm{p} \leq 0.01)$ (width,depth and volume) of all cases include males $\quad \&(\mathrm{p} \leq 0.001)$ respectively and significant difference and females results showed statistically significant in nasopharyngeal (width) (p $\leq 0.05)$. (Table3) differences between control and cleft groups (Fig. 6a,6b and 6c).

TABLE (1) Table showing the effect of grouping ( cleft and control) on different oropharyngeal and nasopharyngeal measurements (All cases).

\begin{tabular}{|c|c|c|c|c|c|c|c|}
\hline & \multirow{3}{*}{ Measurement } & \multicolumn{4}{|c|}{ Group } & \multirow{3}{*}{ t value } & \multirow{3}{*}{$\mathrm{P}$} \\
\hline & & \multicolumn{2}{|c|}{ Control } & \multicolumn{2}{|c|}{ Cleft } & & \\
\hline & & Mean & S.D. & Mean & S.D. & & \\
\hline \multirow{3}{*}{$\begin{array}{c}\text { Oro- } \\
\text { Pharyngeal }\end{array}$} & Width & 23.568 & 4.864 & 20.832 & 5.902 & 1.959 & $0.055 \mathrm{NS}$ \\
\hline & Depth & 11.635 & 3.940 & 8.809 & 2.843 & 3.186 & $0.002 * *$ \\
\hline & Volume & 13198.2 & 4424.1 & 9566.2 & 3466.0 & 3.540 & $0.001 * * *$ \\
\hline \multirow{3}{*}{$\begin{array}{c}\text { Naso- } \\
\text { Pharyngeal }\end{array}$} & Width & 23.409 & 3.477 & 21.009 & 5.151 & 2.116 & $0.039 *$ \\
\hline & Depth & 10.293 & 3.199 & 9.863 & 3.606 & 0.489 & $0.626 \mathrm{NS}$ \\
\hline & Volume & 4072.0 & 1542.4 & 3292.1 & 2466.5 & 1.468 & $0.147 \mathrm{NS}$ \\
\hline
\end{tabular}

S.D. = Standard deviation. $\quad P=$ Probability level for the effect of group (Student t test).

NS= Insignificant $(p>0.05) . \quad *=$ Significant at $p \leq 0.05 \quad * *=$ Significant at $p \leq 0.01 \quad * * *=$ Significant at $p \leq 0.001$ 


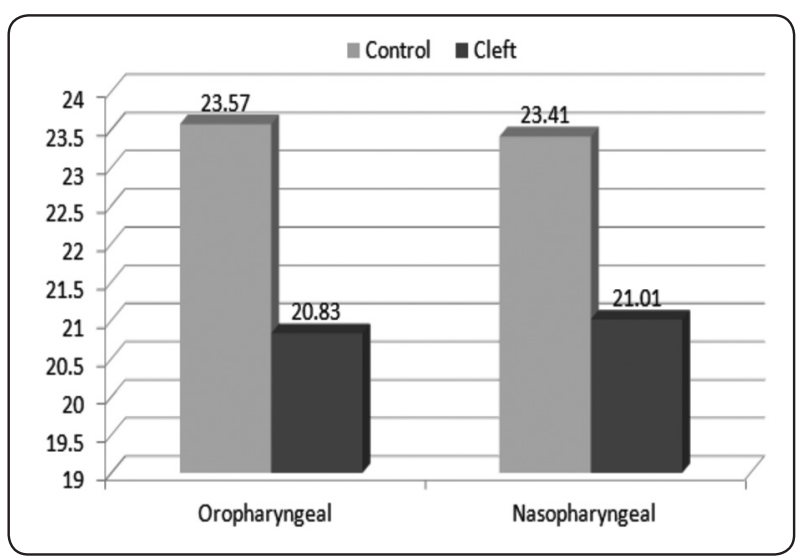

Fig. (6a) Graph showing the mean oropharyngeal and nasopharyngeal width in the control and cleft groups.

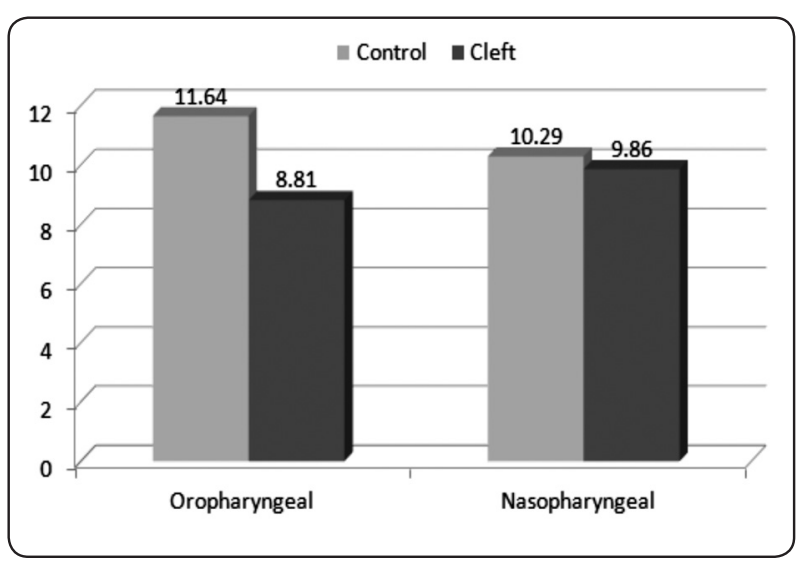

Fig. (6b) Graph showing the mean oropharyngeal and nasopharyngeal depth in the control and cleft groups.

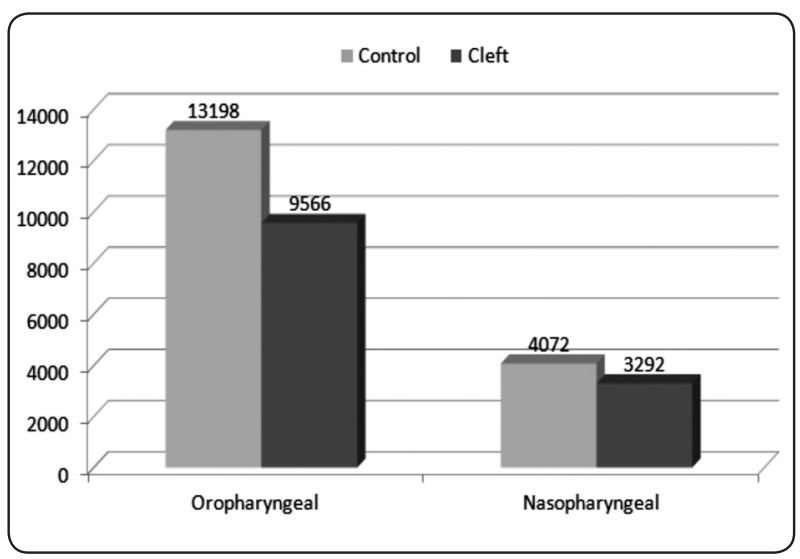

Fig. (6c) Graph showing the mean oropharyngeal and nasopharyngeal volume in the control and cleft groups.

\section{DISCUSSION}

Many studies evaluated the effect of cleft lip and palate on the width, depth and volume of the pharyngeal airway by $2 \mathrm{D}$ and $3 \mathrm{D}$ using $\mathrm{CBCT}$, also several studies evaluated the effect of cleft lip and palate on airway space but there were no researches in Egypt evaluating the effect of cleft lip and palate on airway space.

\section{Effect of cleft lip and palate on pharyngeal air- way (oropharynx and nasopharynx):}

The present study showed statistically significant decrease in oropharyngeal airway (depth and volume) between cleft and control group and insignificant data in nasopharyngeal airway. This results is in agreement with Yoshihara et al, 2012 who evaluated the pharyngeal airway morphology in 34 girls ages range(9-12)years.

On the other hand, Cheung and $\mathrm{Obroi}^{2}$ found that there was no significant difference in pharyngeal airway volume and smallest cross sectional area. Which is different from the present study due to age range $(10,6)$ years and the smaller sample size(7femals ,12 males) furthermore, Rajion et al, $\mathbf{2 0 1 2}^{7}$ demonstrated that there was significant increased nasopharyngeal airway space in cleft lip and palate ,which may be due to the age group (012) month and the smaller sample size. Moreover, Scaf et al, $1991^{8}$ evaluated the nasopharyngeal area in 149 patients with cleft lip and palate and 157 normal individuals age (12-16) years and they found that there was a decreased nasopharygeal airway in cleft group the different in results may be due to different age group.

\section{REFERENCES}

1. Yoshihara M, Terajima M, Yanagita N, Hyakutake H, Kanomi R, Kitahara T, Takahashi I. Three-dimensional analysis of the pharyngeal airway morphology in growing Japanese girls with and without cleft lip and palate. Am J Orthod Dentofacial Orthop. 2012;141(4 Suppl):S92-101.

2. Cheung T, Oberoi S Three dimensional assessment of the pharyngeal airway in individuals with non-syndromic cleft lip and palate 2012;7(8):e43405. 
3. Abramson Z, Susarla S, Troulis M, Kaban L. Age-related changes of the upper airway assessed by 3-dimensional computed tomography. J Craniofac Surg. 2009;20 Suppl $1: 657-63$.

4. Iwasaki T, Hayasaki H, Takemoto $\mathrm{Y}$, Kanomi R, Yamasaki Y. Oropharyngeal airway in children with Class III malocclusion evaluated by cone-beam computed tomography. Am J Orthod Dentofacial Orthop. 2009;136(3):318.e1-9; discussion 318-9.

5. Kyung-Min Oh,a Min-Ah Kim,a Jong-Kuk Youn,b Hyung-Jun Cho,b and Yang-Ho Park. Three-dimensional evaluation of the relationship between nasopharyngeal airway shape and adenoid size in children. 2013 August 22. doi: 10.4041/kjod.2013.43.4.160.

6. Grauer D, Cevidanes L, Styner M, Ackerman J, Proffit W.Pharyngeal airway volume and shape from cone-beam computed tomography: Relationship to facial morphology. Am J Orthod Dentofacial Orthop 2009;136:805-14.
7. Rajion ZA, Al-Khatib AR, Netherway DJ, Townsend GC, Anderson PJ, McLean NR, Samsudin AR The nasopharynx in infants with cleft lip and palate Int $\mathrm{J}$ Pediatr Otorhinolaryngol. 2012;76(2):227-34.

8. Scaf G, Capelozza Filho L, Freitas JA. Assessment of the nasopharyngeal area by cephalometry in cases of cleft lip and palate. J Nihon Univ Sch Dent. 1991 Jun;33(2):98-107.

9. Shigeta Y, Ogawa T, Venturin J, Nguyen M, Clark GT, Enciso R. Gender and age-based differences in computerized tomographic measurements of the oropharynx. Oral Surg Oral Med Oral Pathol Oral Radiol Endod 2008;106:563-70.

10. Martin O, Muelas L, Vinas MJ. Nasopharyngeal cephalometric study of ideal occlusions. Am J Orthod Dentofacial Orthop 2006; 130:436.e1-9.

11. Abramson Z, Susarla S, Troulis M, Kaban L. Age-related changes of the upper airway assessed by 3-dimensional computed tomography. J Craniofac Surg. 2009;20 Suppl 1:657-63. 